\title{
Inibição do crescimento de bactérias Gram-negativas em microdiluição por tratamento com Nisina e EDTA
}

\section{Inhibiting Gram-negative bacteria growth in microdilution by Nisin and EDTA treatment}

\author{
Sidnei Emilio Bordignon-Junior ${ }^{1 *}$, Mitiyo Fukuda Miyaoka ${ }^{1}$, Jefferson da Luz Costa $^{1}$, César \\ Augusto Ticona Benavente ${ }^{2}$, Gustavo Henrique Couto ${ }^{1}$, Carlos Ricardo Soccol ${ }^{1}$. \\ ${ }^{1}$ Departamento de Engenharia de Bioprocessos e Biotecnologia; Universidade Federal do Paraná; 81531-970; \\ Curitiba/PR - Brasil. \\ ${ }^{2}$ Ciências Exatas e Biotecnológicas; Universidade Federal do Tocantins; 77402-970; Gurupi/TO - Brasil.
}

\begin{abstract}
The outer membrane composition of Gram-negative bacteria provides more resistance against the action of antimicrobial agents from the class of bacteriocins, in comparison to Gram-positive bacteria, naturally more susceptible. Aiming the control of proliferation Escherichia coli, Pseudomonas aeruginosa and Salmonella Typhimurium, antimicrobial assays were performed with nisin as biocidal agent (concentrations 123 to 1,111 AU $m L^{-1}$ ) and EDTA as chelating agent, compared to a Gram-positive (Staphylococcus aureus ATCC25923). The susceptibility evaluations were performed in broth microdilution with Mueller-Hinton medium and inoculum with

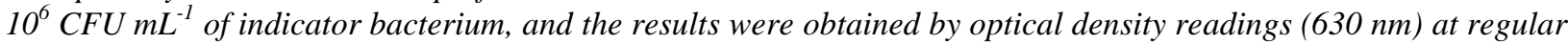
intervals during the incubation period. It was observed that EDTA is capable of reducing cell viability of $\mathrm{P}$. aeruginosa. The bacteriocin nisin demonstrated effective antimicrobial action to four indicator bacteria, under different concentrations. The combined treatments of nisin+EDTA obtained high inhibition rates, and the presence of EDTA was significant only to Gram-negative bacteria. Thus, treatments accounted effective strategies to promote inhibition of cell growth during microdilution broth assays.
\end{abstract}

Key words: antimicrobial, outer membrane, bacteriocin, Salmonella, Escherichia, Pseudomonas, Staphylococcus.

\section{INTRODUÇÃO}

As bacteriocinas representam um grupo de metabólitos protéicos sintetizados por bactérias ácido-lácticas com função antimicrobiana a uma ampla quantidade de bactérias, entre estas, bactérias patogênicas e/ou oportunistas indesejáveis comuns em processos produtivos, especialmente na indústria de alimentos. A nisina representa a primeira substância desta classe comercializada em todo o mundo. É formada por uma cadeia polipeptídica de 34 unidades de aminoácidos, com caráter catiônico e hidrofóbico, tamanho molecular de 3,5 kDa, produzida por espécies de Lactococcus lactis subsp. lactis e estudada desde 1928, de quando datam os registros de sua descoberta (Arauz et al., 2009; Nes et al., 2007). Nas últimas décadas, inúmeras pesquisas buscam comprovar a eficiência de outras substâncias antimicrobianas similares para as mais diversas aplicações científicas, tendo, entretanto, a nisina como referencial que, desde 1988, possui o status GRAS (Generally Regarded as Safe) e por isso tem seu uso autorizado como aditivo alimentar, particularmente na fabricação de queijos, requeijão e derivados cárneos em muitos países (Arauz et al., 2009; Zacharof \& Lovitt, 2012). Há, entretanto, uma característica intrínseca limitante a esta classe de biomoléculas que as impede de

Author for correspondence: bordig@gmail.com 
uma maior empregabilidade no controle de micro-organismos. Seu espectro de atividade inibitório é naturalmente limitado a bactérias taxonomicamente próximas à linhagem produtora, assim, são mais susceptíveis as bactérias Gram-positivas, incluindo os gêneros Lactococcus, Streptococcus, Staphylococcus, Micrococcus, Pediococcus, Lactobacillus, Listeria e Mycobacterium (Arauz et al., 2009), além de Bacillus cereus (Shimizu et al., 1999) e Clostridium botulinum (Daeschel et al., 1991), com menor frequência. Fungos e leveduras são naturalmente resistentes à ação das bacteriocinas, já bactérias Gram-negativas, habitualmente resistentes, podem apresentar sensibilidade à nisina quando em altas concentrações e, ainda, se expostas ou prétratadas com substâncias (ácidos, detergentes, quelantes) ou tratamentos físicos (choque osmótico) que alterem a estabilidade e causem danos à membrana externa das células, estrutura que as torna diferenciadas das Gram-positivas quanto à resistência (Parada et al., 2007; Branen \& Davidson, 2004; Castellano et al., 2011; Vuyst \& Leroy, 2007). O Etileno-diaminotetra-acetato (EDTA) é o agente quelante mais utilizado nestas aplicações e tem sido extensivamente estudado através de combinações com algum agente biocida, como antibiótico, lisozima ou bacteriocina (Stevens et al., 1991; Gao et al., 1999; Helander et al., 2000). Os objetivos deste estudo foram: (i) estabelecer as concentrações inibitórias de nisina contra quatro bactérias-alvo, sendo três Gramnegativas, e uma Gram-positiva, e (ii) avaliar a contribuição do EDTA através de um tratamento combinado entre EDTA e Nisina sob as células-alvo, utilizando a técnica de microdiluição em caldo.

\section{MATERIAIS E MÉTODOS}

\section{Micro-organismos e meios de cultivo}

Três bactérias Gram-negativas foram utilizadas como micro-organismos indicadores para os ensaios de atividade antimicrobiana, sendo: Escherichia coli, Salmonella enterica subsp. enterica sorotipo Typhimurium e Pseudomonas aeruginosa. Além destas, uma linhagem Gram-positiva foi avaliada sob as mesmas condições como modelo de comparação, sendo esta Staphylococcus aureus ATCC25923. As linhagens Gram-negativas patogênicas representam isolados clínicos previamente obtidos de fezes de animais e pertencem ao Laboratório de Processos Biotecnológicos (LPB) da Universidade Federal do Paraná (UFPR), Brasil. Todas as bactérias foram pré-cultivadas em caldo $\mathrm{BHI}, 37^{\circ} \mathrm{C}, 16-18$ horas antes dos ensaios, a partir de culturas estocadas em ultrafreezer a $-80^{\circ} \mathrm{C}$. O caldo Mueller-Hinton (MH) foi o meio de cultura utilizado nas avaliações antimicrobianas, conforme recomendado pelo CLSI "Clinical and Laboratory Standards Institute, USA" (NCCLS, 2003).

\section{Padronização de inóculo e curva de crescimento}

Um inóculo padronizado em $10^{6} \mathrm{UFC} \mathrm{mL}^{-1}$ de cada micro-organismo indicador foi preparado a partir dos pré-cultivos, submetidos à diluição decimal seriada (água peptonada $0,1 \%$ ) até turbidez equivalente a solução 0,5 MacFarland, determinada pela leitura da absorbância $(\lambda=630 \mathrm{~nm})$ em espectrofômetro (Spectrum SP2000) entre 0.080 e 0.100 . Neste intervalo de densidade óptica, a suspensão celular contém, aproximadamente, $1,0 \times 10^{8}$ UFC $\mathrm{mL}^{-1}$ (NCCLS, 2003), portanto, prosseguia-se com mais duas diluições para obtenção dos inóculos finais com $10^{6} \mathrm{UFC} \mathrm{mL}^{-1}$.

A curva de crescimento de cada uma das quatro bactérias-alvo foi individualmente determinada para o método de microdiluição em caldo utilizando microplaca com 96 poços de fundo redondo. Cada poço recebeu, em quintuplicata, $160 \mu \mathrm{L}$ de caldo $\mathrm{MH}$ esterilizado e $20 \mu \mathrm{L}$ de inóculo padronizado (população final de $2,0 \times 10^{4} \mathrm{UFC} /$ poço), totalizando $180 \mu \mathrm{L} /$ poço de volume final. 
Nenhuma substância inibitória foi utilizada nesta avaliação. As microplacas permaneceram incubadas em estufa bacteriológica a $37^{\circ} \mathrm{C}$ durante 24 horas, com medidas de absorbância $(\lambda=630 \mathrm{~nm})$ a cada 3 horas, em espectrofotômetro tipo leitor de ELISA (BioTek "Power Wave" XS), e programa KC Junior para coleta dos dados. Os resultados foram registrados através do incremento na densidade óptica (média das leituras de Abs $_{630 \mathrm{~nm}}$ ) de cada microorganismo em função do tempo, em horas.

\section{Ensaio preliminar com EDTA}

A multiplicação da bactéria Pseudomonas aeruginosa foi avaliada somente na presença de EDTA através de quatro soluções de concentração $0,1 \mathrm{mM}, 1,0 \mathrm{mM}, 3,0 \mathrm{mM}$ e 10,0 mM, aplicadas em volume de $10 \mu \mathrm{L}(-1)$ ou $20 \mu \mathrm{L}(+1)$ por poço, em triplicata. A adição do inóculo foi conforme descrito acima, e o caldo $\mathrm{MH}$ foi aplicado em volume complementar até completar $180 \mu \mathrm{L}$ totais. A avaliação dos resultados, por medida da densidade óptica $(\lambda=630 \mathrm{~nm})$, se deu somente ao final de 24 horas de incubação a $37^{\circ} \mathrm{C}$. A partir de um controle, que não recebeu solução de EDTA, foi possível avaliar se o agente quelante, sob suas diferentes concentrações, interferia no crescimento da bactéria-alvo. Os resultados foram expressos como viabilidade celular, em percentual, obtida pela diferença da média de leituras de absorbância ( $\mathrm{Abs}_{630 \mathrm{~nm}}$ ) entre cada tratamento e o controle.

\section{Ensaios de susceptibilidade à nisina}

Uma solução-mãe da bacteriocina nisina (Nisaplin, Sigma-Aldrich ${ }^{\circledR}$ ) foi preparada em $\mathrm{HCl}$ 0,02 $\mathrm{N}$ na concentração de 10.000 unidades arbitrárias por mililitro $\left(\mathrm{UA} \mathrm{mL} \mathrm{mL}^{-1}\right.$ ), e distribuída, em triplicata, nas placas de microdiluição em volumes de 20, 30, 40, 50 e $60 \mu \mathrm{L}$ para cada uma das quatro bactériasalvo. Em seguida, cada poço recebeu $20 \mu \mathrm{L}$ de inóculo padronizado (como descrito acima) e volumes complementares de caldo $\mathrm{MH}(140,130,120,110$ e $100 \mu \mathrm{L})$ até totalizar $180 \mu \mathrm{L}$ poço. A concentração final de nisina foi crescente e correspondente a $123 \mathrm{UA} \mathrm{mL}^{-1}, 278 \mathrm{UA} \mathrm{mL}^{-1}, 493 \mathrm{UA} \mathrm{mL}^{-1}$, 771 UA $\mathrm{mL}^{-1}$ e 1.111 UA $\mathrm{mL}^{-1}$, respectivamente. As placas permaneceram incubadas a $37^{\circ} \mathrm{C}$ por um período total de 24 horas, com leituras de absorbância $(\lambda=630$ nm) às 3, 6, 9 e 24 horas. A coleta dos dados foi realizada conforme descrito, e os resultados obtidos através do incremento da densidade óptica nas amostras em função do tempo. Os resultados foram expressos como taxa de inibição, um índice percentual (\%) que representou a diferença da média de absorbância de cada tratamento em relação ao crescimento controle (sem tratamento com nisina).

Os melhores resultados de inibição de nisina para cada bactéria-alvo, somado àquela concentração de EDTA que não causou mortalidade celular própria do agente quelante, foram combinados e avaliados sob as mesmas condições contra os quatro micro-organismos indicadores em microdiluição em caldo.

\section{Análise dos dados experimentais}

Os resultados foram analisados pela análise da variância (ANOVA) - no programa SAS 9.1, sendo os três fatores considerados como efeitos fixos.

\section{RESULTADOS E DISCUSSÃO}

As curvas de crescimento celular foram estabelecidas para as quatro bactérias-alvo nas condições do ensaio (Fig. 1).

Com estes dados foi possível reconhecer as fases de multiplicação próprias de cada cultura e estabelecer os pontos mais apropriados de leitura para os bioensaios de inibição. Foi detectada a fase lag mais prolongada em Pseudomonas aeruginosa (6 horas), enquanto nas demais esta fase foi de até 4 horas. Com 9 horas de cultivo, todas as culturas encontravam-se homogeneamente na fase logarítmica de reprodução, sendo este o ponto-chave escolhido para as 


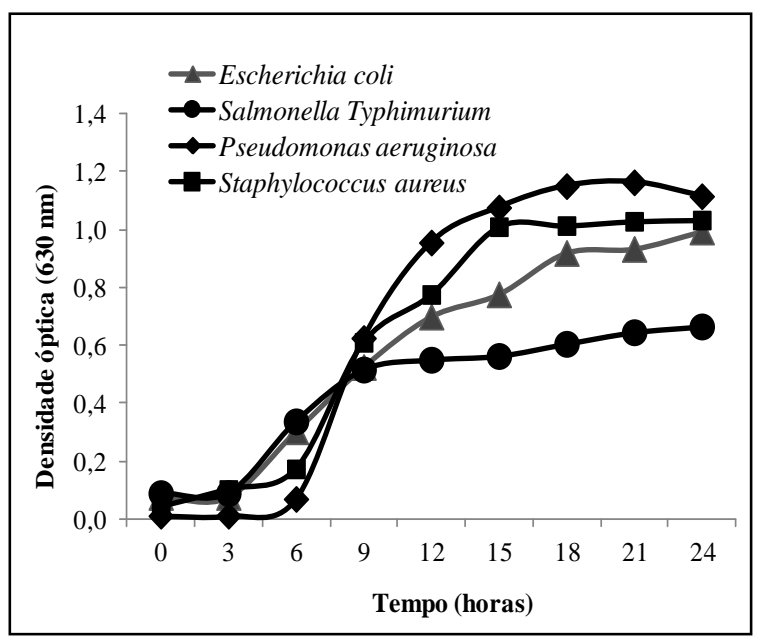

Figura 1 - Cinética de crescimento celular para as bactérias-alvo avaliadas em microdiluição.

avaliações posteriores de inibição, uma vez que é mais recomendável avaliar a ação de compostos antimicrobianos sob esta fase do crescimento bacteriano, que representa células metabolicamente ativas e energizadas (Thomas et al., 2000). Castellano et al. (2003) corroboram com esta hipótese, uma vez que observaram em seus estudos resultados de mortalidade mais efetivos contra Escherichia coli neste momento do que nas fases de adaptação (lag) ou estacionária.

$\mathrm{O}$ agente quelante EDTA exerceu efeito inibitório nos tratamentos de maior concentração, constatado a partir da diminuição da densidade óptica de Pseudomonas aeruginosa a partir do tratamento 2B (Fig. 2). A viabilidade celular da bactéria-alvo foi inversamente proporcional ao aumento na concentração do quelante no ensaio, que sob o tratamento de maior concentração (4B) chegou a comprometer mais de $30 \%$ da população em relação ao controle. Por outro lado, os três primeiros tratamentos não afetaram significativamente a multiplicação de $P$. aeruginosa, constatado pela similaridade entre a viabilidade dos referidos tratamentos e do controle (sem EDTA). Dessa maneira, o tratamento $2 \mathrm{~A}(10 \mu \mathrm{L}$ da solução $1,0 \mathrm{mM}$ EDTA) ficou estabelecido como o mais apropriado por não interferir na viabilidade bacteriana. Resultados similares com Pseudomonas aeruginosa ATCC 9027 foram descritos por Helander et al. (2000).

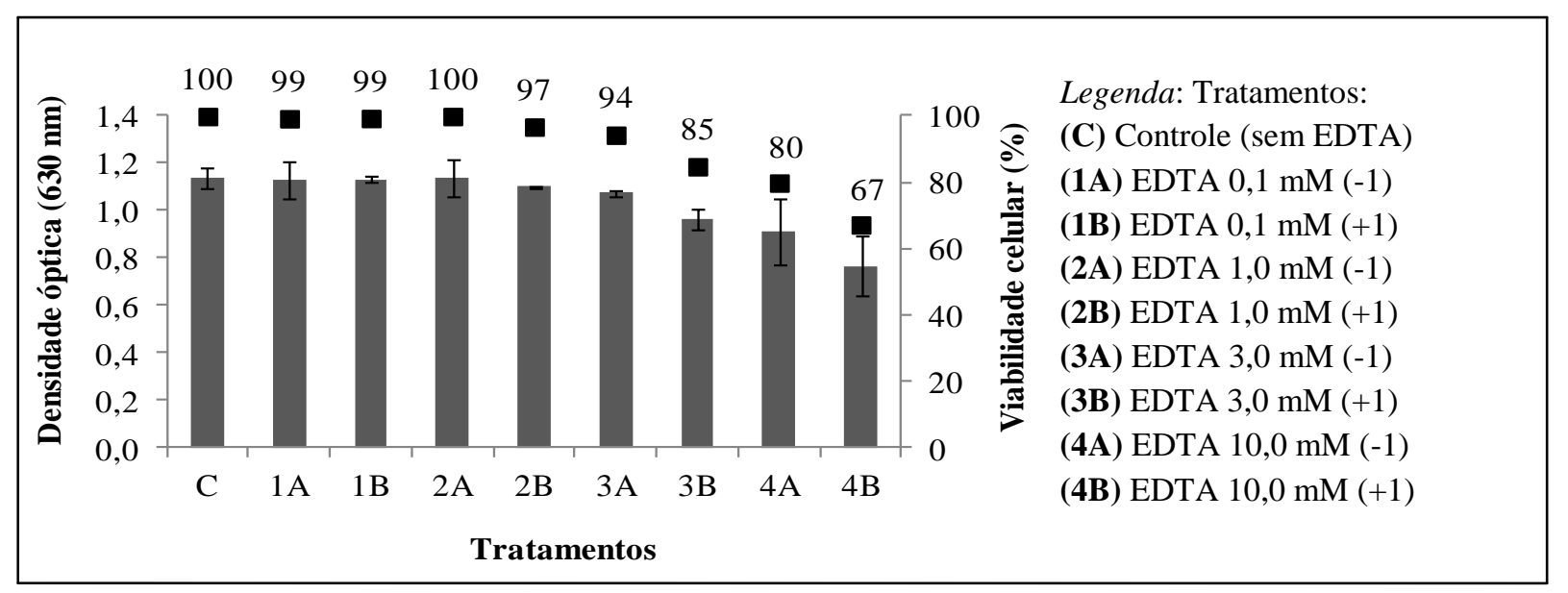

Figura 2 - Tratamentos com EDTA e viabilidade celular de Pseudomonas aeruginosa.

A ação inibitória própria do EDTA nas soluções de maior concentração pode ser explicada pela grave limitação na disponibilidade de cátions divalentes (especialmente $\mathrm{Ca}^{2+}$ e $\mathrm{Mg}^{2+}$ ) que exercem funções de ligantes entre as macromoléculas 
das membranas celulares, ocasionando certa desestabilização desta unidade e, consequentemente, alteração no equilíbrio osmótico das células (Economou et al., 2009). Por outro lado, é possível beneficiarse deste mesmo efeito quelante sem afetar a viabilidade celular, fazendo uso de solução de menor concentração, que simplesmente favoreça a introdução das macromoléculas de interesse, neste caso a nisina, através da membrana externa (Vaara, 1992).

A ação antimicrobiana da nisina sobre as bactérias-alvo foi avaliada inicialmente sem EDTA, empregando somente concentrações crescentes da bacteriocina. Todas as bactérias se mostraram susceptíveis, porém em diferentes concentrações. Para Escherichia coli (Fig. 3-A) e Pseudomonas aeruginosa (Fig. 3-B), houve ação bactericida apenas sob a máxima concentração avaliada (1.111 UA $\mathrm{mL}^{-1}$ ), quando não foi detectada multiplicação celular em 24 horas. Até 9 horas de incubação, $493 \mathrm{UA} \mathrm{mL}^{-1}$ foram suficientes para impedir o crescimento de E. coli, enquanto, no mesmo período, $P$. aeruginosa demonstrou-se mais sensível, pois foi inibida com 278 UA $\mathrm{mL}^{-1}$. Sob estas concentrações, estima-se um efeito bacteriostático, capaz de retardar a multiplicação celular, porém sem causar a mortalidade completa das células na presença do agente antimicrobiano.

As linhagens de Salmonella Typhimurium e Staphylococcus aureus ATCC25923 apresentaram maior susceptibilidade à nisina e ambas foram completamente inibidas na presença de $493 \mathrm{UA} \mathrm{mL}^{-1}$ por até 24 horas. Apenas nos tratamentos com 123 e 278 UA $\mathrm{mL}^{-1}$ foi registrado crescimento celular retardatário em 24 horas de incubação (Fig. 3-C e 3-D).
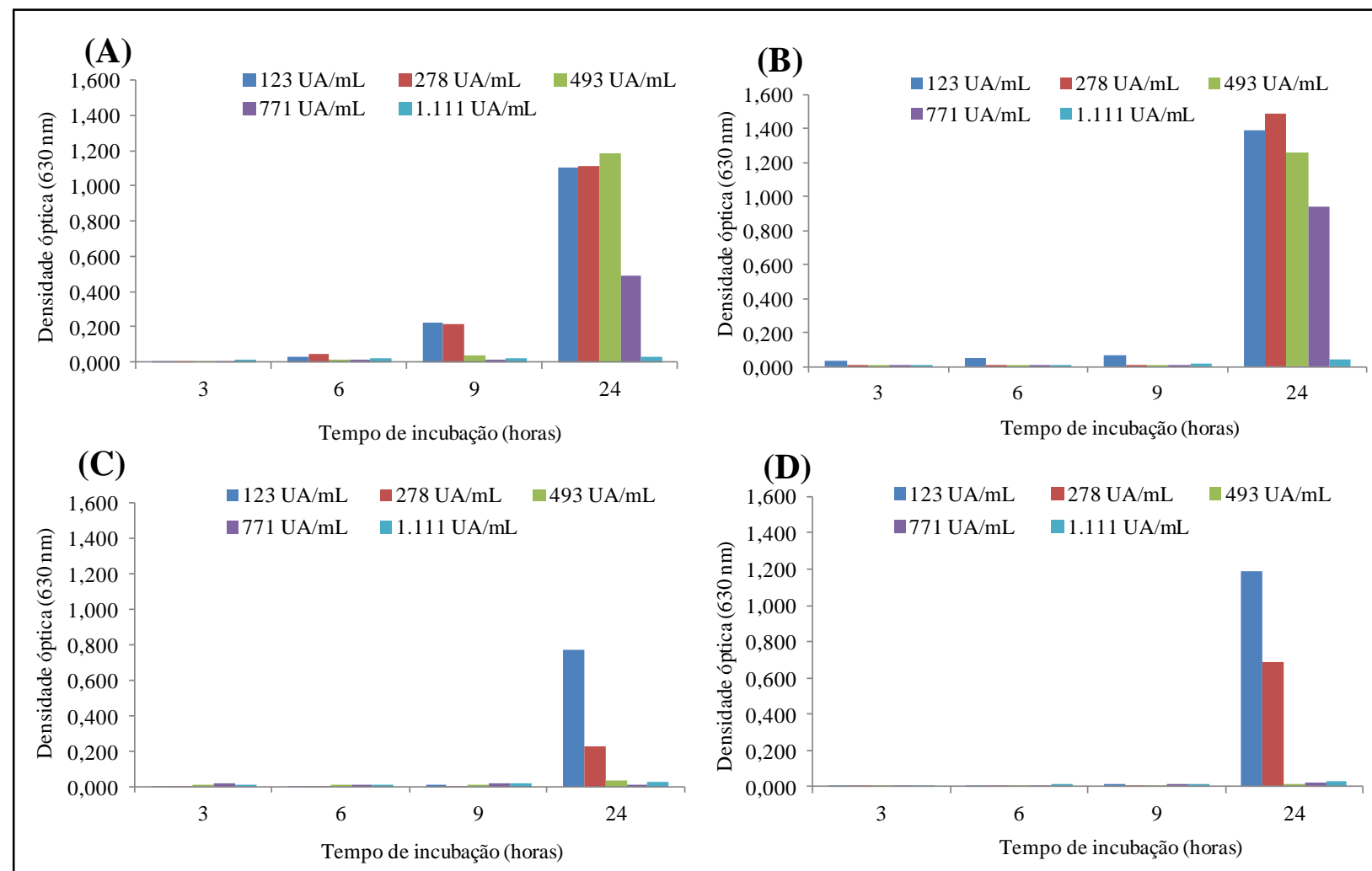

(A) Escherichia coli; (B) Pseudomonas aeruginosa; (C) Salmonella Typhimurium; (D) Staphylococcus aureus.

Figura 3 - Susceptibilidade de bactérias-alvo aos tratamentos com diferentes concentrações de nisina. 
Fazendo uso do tratamento 2A de EDTA combinado às concentrações inibitórias de nisina para cada uma das bactérias indicadoras (Fig. 3), foi realizado um ensaio final a fim de confirmar o potencial inibitório do tratamento misto e verificar se a presença do EDTA seria significativa no incremento do potencial biocida contra as referidas bactérias, especialmente as Gramnegativas. Os percentuais de inibição do tratamento misto estão apresentados através da Tabela 1, comparativamente aos valores de inibição obtidos anteriormente por ação exclusiva da nisina. A eficiência dos tratamentos de nisina+EDTA foi alta $\mathrm{e}$ manteve-se acima de $97 \%$ de inibição, tanto durante a fase exponencial ( 9 horas), quanto na fase estacionária (24 horas), para todas as bactérias-alvo. Tais resultados já eram esperados, uma vez que tratamentos combinados de nisina e EDTA são reportados como efetivos contra linhagens de E. coli, Salmonella Enteritidis e Pseudomonas fluorescens (Branen \& Davidson, 2004), Pseudomonas spp. e contagem total de Enterobacteriaceae (Economou et al., 2008). De maneira geral, nota-se que o controle da multiplicação celular destas linhagens foi favorecido pela presença do EDTA nos ensaios de microdiluição, exceto para Staphylococcus aureus às 9 horas de incubação.

Tabela 1 - Taxas de inibição para tratamentos de nisina e nisina+EDTA contra bactérias-alvo.

\begin{tabular}{lcccc}
\hline \multirow{2}{*}{ Micro-organismo indicador } & \multicolumn{2}{c}{9 horas } & \multicolumn{2}{c}{ 24 horas } \\
\cline { 2 - 5 } & Nisina & Nisina+EDTA & Nisina & Nisina+EDTA \\
\hline Escherichia coli & $95,0 \%$ & $97,4 \%$ & $96,6 \%$ & $98,0 \%$ \\
Pseudomonas aeruginosa & $97,6 \%$ & $98,9 \%$ & $96,6 \%$ & $98,7 \%$ \\
Salmonella Typhimurium & $96,1 \%$ & $99,0 \%$ & $98,5 \%$ & $100,0 \%$ \\
Staphylococcus aureus & $98,9 \%$ & $98,8 \%$ & $94,2 \%$ & $97,6 \%$ \\
\hline
\end{tabular}

A Tabela 2 permite testar as diferenças observadas na Tabela 1 e ainda verificar se há interação entre os fatores. Foi observada diferença significativa $(\mathrm{p}<0,05)$, como já era esperado, entre os micro-organismos do ensaio, e, também, quanto ao tratamento de inibição empregado (na ausência ou presença de EDTA), entretanto, observou-se que tal efeito não foi obtido exclusivamente pela ação do EDTA, mas pela interação deste com o fator "micro-organismo". O fator "hora" (avaliação em 9 ou 24 horas) não foi significativo, no entanto apresenta interação com "micro-organismo" (HxMO) $\mathrm{p}<0,01$. Tais eventos são comprovados pelos desdobramentos das interações Tabela 3.
Tabela 2 - ANOVA para taxas de inibição de tratamentos de nisina e nisina+EDTA. ( $\mathrm{FV}=$ Fonte de variação, $\mathrm{GL}=$ graus de liberdade, QM=quadrado médio).

\begin{tabular}{l|c|l}
\hline \multicolumn{1}{c|}{$\boldsymbol{F} \boldsymbol{V}$} & $\boldsymbol{G} \boldsymbol{c}$ & \multicolumn{1}{c}{$\boldsymbol{Q M}$} \\
\hline Tratamento (T) & 1 & $77,47^{* *}$ \\
Hora (H) & 1 & $0,00^{\text {n.s }}$ \\
Micro-organismo (MO) & 3 & $14,10^{* *}$ \\
TxH & 1 & $0,00^{\text {n.s }}$ \\
TxMO & 3 & $19,90^{* *}$ \\
HxMO & 3 & $6,28^{*}$ \\
TxHxMO & 3 & $2,10^{\text {n.s }}$ \\
Erro & 105 & 1,93 \\
\hline Média & 97,92 \\
CV $(\%)$ & 1.41
\end{tabular}

*,**: significativo $\alpha=0,05$ e 0,01 , respectivamente. n.s.: não significativo $\alpha=0,05$. 
A presença de EDTA nos ensaios não se mostrou significativa apenas para Staphylococcus aureus ATCC25923 (Tabela 3). A composição da parede celular Grampositiva permite a esta bactéria maior robustez quanto aos ataques de sensibilização da membrana (Vaara, 1992), sendo, dessa forma, desnecessário o tratamento complementar de EDTA à nisina, para $S$. aureus. Por outro lado, vemos que a ação isolada de nisina já garantiu uma alta mortalidade das células Gram-positivas referidas, fato que justifica o maior índice de inibição $(98,9 \%)$ observado às 9 horas de ensaio no tratamento somente com a bacteriocina. Na Figura 4 estão representado o comportamento da interação TxMO de cada bactéria, onde fica evidente a contribuição do EDTA sob o incremento da ação antimicrobiana de $E$. coli, $P$. aeruginosa e $S$. Typhimurium.

Complementarmente, o desdobramento da interação HxMO, micro-organismo dentro de horas (Tabela 3 ) revelou que para E. coli há diferença significativa entre o tempo das avaliações, fato não observado entre as demais bactérias-alvo. Sendo as médias de inibição para esta bactéria de 96,26\% (9 horas) e $97,33 \%$ (24 horas).

Tabela 3 - ANOVA para inibição do crescimento microbiano. Micro-organismo dentro de tratamentos $(\mathrm{MO} / \mathrm{T})$ e dentro de horas $(\mathrm{MO} / \mathrm{H})$.

\begin{tabular}{|c|c|c|c|}
\hline \multirow{2}{*}{$F \boldsymbol{V}$} & \multirow{2}{*}{$G L$} & \multicolumn{2}{|c|}{$Q M$} \\
\hline & & $M O / T$ & $\mathrm{MO} / \mathrm{H}$ \\
\hline Escherichia coli & 1 & $21,97 * *$ & $8,34 * *$ \\
\hline $\begin{array}{l}\text { Pseudomonas } \\
\text { aeruginosa }\end{array}$ & 1 & $24,66^{* *}$ & $3,64^{\mathrm{n} . \mathrm{s}}$ \\
\hline $\begin{array}{l}\text { Salmonella } \\
\text { Typhimurium }\end{array}$ & 1 & $88,01 * *$ & $1,84^{\mathrm{n} . \mathrm{s}}$ \\
\hline $\begin{array}{l}\text { Staphylococcus } \\
\text { aureus }\end{array}$ & 1 & $2,10^{\mathrm{n} . \mathrm{s}}$ & $5,02^{\text {n.s }}$ \\
\hline
\end{tabular}

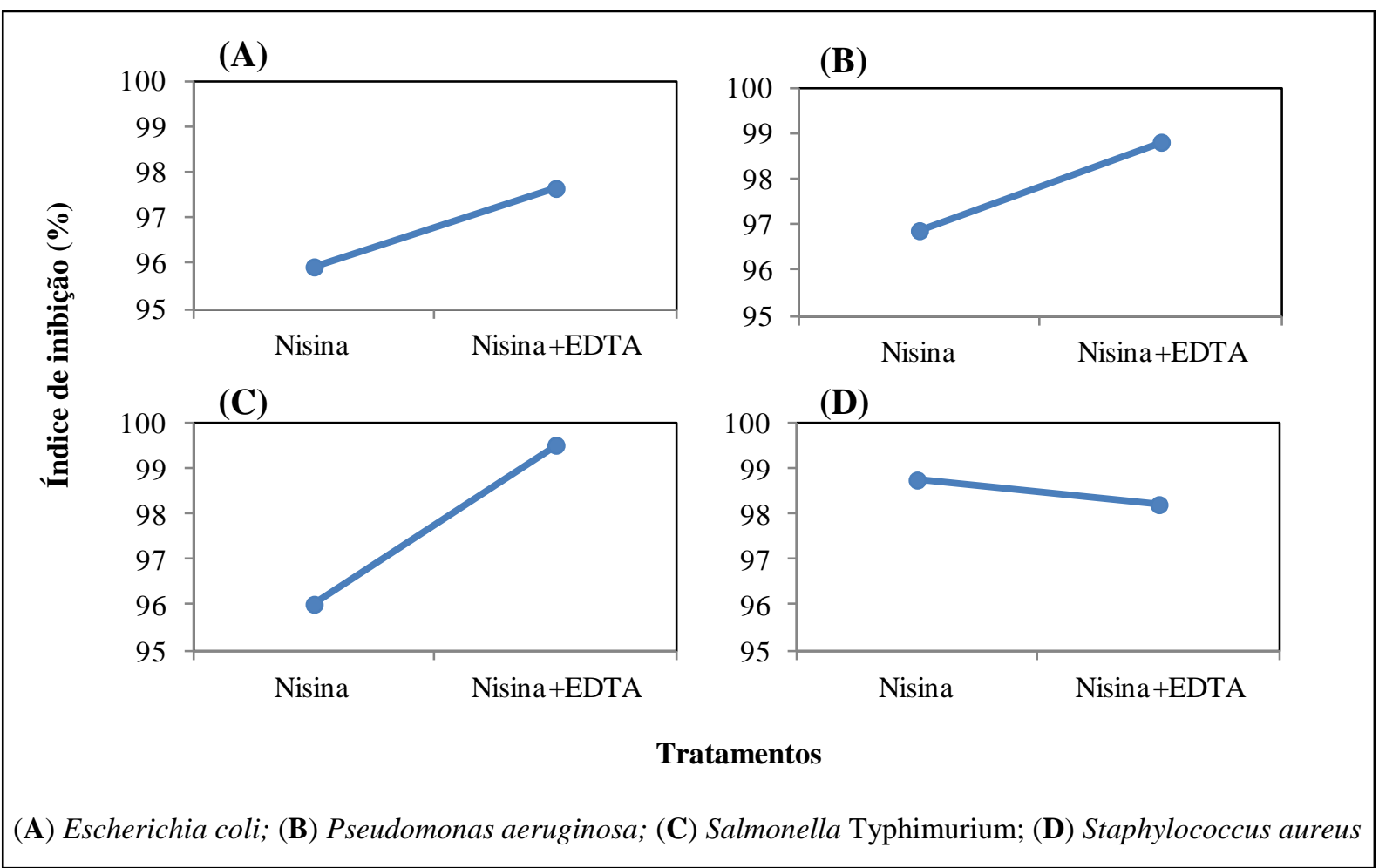

Figura 4 - Representação gráfica da interação Tratamento x Micro-organismo (TxMO). 


\section{CONCLUSÕES}

A partir das curvas de crescimento microbiano foi possível estabelecer o período mais apropriado para as avaliações antimicrobianas sob as fases de crescimento exponencial das bactérias-alvo, às 9 horas de incubação, conforme as condições do ensaio em microdiluição descritas.

O EDTA isoladamente é capaz de reduzir a viabilidade celular de Pseudomonas aeruginosa, assim foi estabelecido o tratamento $2 \mathrm{~A}(10 \mu \mathrm{L}$ da solução $1,0 \mathrm{mM})$ como o mais apropriado, pois não foi observada inibição sob esta concentração do composto em comparação à amostracontrole (sem EDTA).

Nisina exerceu ação antimicrobiana efetiva (durante 24 horas) sobre os quatro microorganismos indicadores, sendo o perfil de susceptibilidade observado o seguinte: Salmonella Typhimurium e Staphylococcus aureus ATCC25923 (493 UA mL $\mathrm{UL}^{-1}$ ) $>P$. aeruginosa e Escherichia coli (1.111 UA $\left.\mathrm{mL}^{-1}\right)$.

Os tratamentos combinados de nisina+EDTA obtiveram altas taxas de inibição (> 97\%) para as quatro bactérias, entretanto sua ação junto à nisina foi significativa frente às três bactérias Gramnegativas, e não significativa para Staphylococcus aureus ATCC25923.

Escherichia coli foi a única dentre as bactérias-alvo que foi significativamente mais susceptível aos tratamentos em função do tempo de ensaio.

Os tratamentos com nisina (S. aureus) e nisina+EDTA (bactérias Gram-negativas) representaram estratégias efetivas de inibição do crescimento celular durante a realização de ensaios antimicrobianos em microdiluição em caldo, podendo ser usados como referências de controle positivo para estas análises.

\section{AGRADECIMENTOS}

A Dra. Sascha Habu pelo conhecimento compartilhado acerca dos ensaios antimicrobianos.

\section{RESUMO}

A composição da membrana celular das bactérias Gram-negativas garante maior resistência à ação de agentes antimicrobianos da classe das bacteriocinas em relação às Gram-positivas, naturalmente mais susceptíveis. Visando controlar a multiplicação de Escherichia coli, Pseudomonas aeruginosa, Salmonella $S$. Typhimurium, foram realizados ensaios antimicrobianos com nisina como agente biocida (concentrações de 123 a 1.111 UA $\mathrm{mL}^{-1}$ ) e EDTA como agente quelante, comparativamente a uma bactéria Grampositiva (Staphylococcus aureus ATCC 25923). As avaliações de susceptibilidade foram realizadas por microdiluição em caldo, utilizando meio Mueller-Hinton e inóculo com $10^{6}$ UFC $\mathrm{mL}^{-1}$ das bactérias indicadoras, sendo os resultados obtidos por densidade óptica $(630 \mathrm{~nm})$ em intervalos regulares durante o período de incubação. Foi observado que EDTA é capaz de reduzir a viabilidade celular de $P$. aeruginosa. A bacteriocina nisina exerceu ação antimicrobiana efetiva sobre as quatro bactérias indicadoras, sob diferentes concentrações. Tratamentos combinados de nisina+EDTA obtiveram altas taxas de inibição, sendo a presença do EDTA significativa apenas para as bactérias Gramnegativas. Dessa forma, os tratamentos promovidos representaram estratégias efetivas de inibição do crescimento celular durante a realização de ensaios antimicrobianos em microdiluição em caldo.

Palavras-chave: antimicrobiano, membrana, bacteriocina, Salmonella, Escherichia, Pseudomonas, Staphylococcus.

\section{REFERÊNCIAS}

ARAUZ, L. J.; JOZALA, A. F.; MAZZOLA, P. G.; PENNA, T. C. V. Nisin biotechnological production and application : a review. Trends in Food Science \& Technology, v. 20, p. 146-154, 2009. 
BRANEN, J. K.; DAVIDSON, P. M. Enhancement of nisin, lysozyme and monolaurin antimicrobial activities by ethylenediaminetetraacetic acid and lactoferrin. International Journal of Food Microbiology, v. 90, p. $63-74,2004$.

CASTELLANO, P.; BELFIORE, C.; VIGNOLO, G. Combination of bioprotective cultures with EDTA to reduce Escherichia coli $\mathrm{O} 157$ : $\mathrm{H} 7$ in frozen groundbeef patties. Food Control, v. 22, n. 8, p. 1461-1465, 2011.

CASTELlANO, P.; RAYA, R.; VIGNOLO, G. Mode of action of lactocin 705 , a two-component bacteriocin from Lactobacillus casei CRL705. International Journal of Food Microbiology, v. 85, p. 35-43, 2003.

DAESCHEL, M.A.; JUNG, D-S.; WATSON, B.T. Controlling wine malolactic fermentation with nisin and nisin-resistant strains of Leuconostoc oenos. Applied and Environmental Microbiology, v. 57, n. 2, p. 601-603, 1991.

ECONOMOU, T.; POURNIS, N.; NTZIMANI, A.; SAVVAIDIS, I. N. Nisin - EDTA treatments and modified atmosphere packaging to increase fresh chicken meat shelf-life. Food Chemistry, v. 114, n. 4, p. 1470-1476, 2009.

GAO, Y.; VAN BELKUM, M. J.; STILES, M. E. The Outer Membrane of Gram-Negative Bacteria Inhibits Antibacterial Activity of Brochocin-C. Applied and Environmental Microbiology, v. 65, n. 10 , p. $4329-4333,1999$.

HELANDER, I. M.; MATTILA-SANDHOLM, T. Permeability barrier of the Gram-negative bacterial outer membrane with special reference to nisin. International Journal of Food Microbiology, v. 60, p. $153-61,2000$.

NCCLS. Performance Standards for Antimicrobial Disk Susceptibility Tests: Approved Standard - Eighth Edition. NCCLS document M2-A8. Wayne, Pennsylvania: NCCLS, 2003.

NES, I. F.; YOON, S.-S.; DIEP, D. B. Ribosomally Synthesiszed Antimicrobial Peptides (Bacteriocins) in Lactic Acid Bacteria: A Review. Food Science and Biotechnology, v. 16, n. 5, p. 675 - 690, 2007.

PARADA, J. L.; CARON, C. R.; MEDEIROS, A. B. P.; SOCCOL, C. R. Bacteriocins from Lactic Acid Bacteria: Purification, Properties and use as Biopreservatives. Brazilian Archives of Biology and Technology, v. 50, n. 3, p. 521-542, 2007.
SHIMIZU, H.; MIZUGUCHI, T.; TANAKA, E.; SHIOYA, S. Nisin Production by a Mixed-Culture System Consisting of Lactococcus lactis and Kluyveromyces marxianus. Applied and Environmental Microbiology, v. 65, n. 7, p. 31343141, 1999.

STEVENS, K. A.; SHELDON, B. W.; KLAPES, N. A.; KLAENHAMMER, T. R. Nisin Treatment for Inactivation of Salmonella Species and Other GramNegative Bacteria. Applied and Environmental Microbiology, v. 57, n. 12, p. 3613-3615, 1991.

THOMAS, L.V.; CLARKSON, M.R.; DELVESBROUGHTON, J. Nisin. In: NAIDU, A.S. Natural Food Antimicrobial Systems. New York: CRC Press, p. 463-524, 2000.

VAARA, M. Agents That Increase the Permeability of the Outer Membrane. Microbiological Reviews, v. 56, n. 3, p. 395-411, 1992.

VUYST, L. D.; LEROY, F. Bacteriocins from Lactic Acid Bacteria : Production, Purification, and Food. Journal Molecular Microbiology Biotechnology, v. 13, p. 194-199, 2007.

ZACHAROF, M. P.; LOVITT, R. W. Bacteriocins Produced by Lactic Acid Bacteria - A Review Article. APCBEE Procedia, v. 2, p. 50 - 56, 2012. 